\title{
X-ray Diffraction Study of the Ordered Structures and Phase Relation in Pd-Mn Alloy System
}

\author{
Suo Yin ${ }^{1}$, Miwako Takahashi ${ }^{1}$, Rokuro Miida ${ }^{2}$, Hiroshi Iwasaki ${ }^{1}$ and Ken-ichi Ohshima ${ }^{1, *}$ \\ ${ }^{1}$ Insititute of Materials Science, University of Tsukuba, Tsukuba 305-8573, Japan \\ ${ }^{2}$ Tokyo University of Science, Suwa, Chino 391-0292, Japan
}

\begin{abstract}
This paper reports the results of structural study on the ordered phases formed in Pd-rich Pd-Mn alloys adopting X-ray powder diffraction method. Formations of the tetragonal $\mathrm{DO}_{23}$-type $\mathrm{Pd}_{3} \mathrm{Mn}$, orthorhombic $\mathrm{Pd}_{2} \mathrm{Mn}$ and orthorhombic $\mathrm{Pd}_{5} \mathrm{Mn}_{3}$ reported by previous researchers have been confirmed. Rietveld refinement of the diffraction data of the latter two phases has determined precisely the atomic parameters and revealed the significance of the shifts of atoms in $\mathrm{Pd}_{2} \mathrm{Mn}$. It is shown that the $\mathrm{L1}_{0}$-type phase extends to about 33 at $\%$ Mn at high temperatures and $\mathrm{Pd}{ }_{2} \mathrm{Mn}$ and $\mathrm{Pd}_{5} \mathrm{Mn}_{3}$ form via two-step ordering from the $\mathrm{L1}_{0}$-type phase. A revised phase diagram on the Pd-rich side has been proposed. Discussion is given on the stability of the relevant ordered phases by making calculation of the total energy by the density functional method. [doi:10.2320/matertrans.M2010372]
\end{abstract}

(Received October 26, 2010; Accepted December 17, 2010; Published February 25, 2011)

Keywords: palladium-manganese alloy, ordered structure, X-ray diffraction, atomic phase diagram

\section{Introduction}

In the past 50 years, structural studies were made for the phases forming on the Pd-rich side of the Pd-Mn alloy system. Primary solid solution of Pd with the face-centered cubic (fcc) structure extends up to about 30\% Mn (All the percentages in the present paper refer to atomic \%.) and an ordered phase $\mathrm{Pd}_{3} \mathrm{Mn}$ was found by Watanabe ${ }^{1)}$ by electron diffraction at the composition of $25 \% \mathrm{Mn}$. It has a longperiod structure based on the $\mathrm{L}_{2}$-type one and is isostructural to the $\mathrm{DO}_{23}$-type structure. Sato and Toth ${ }^{2)}$ attributed the stability of the long-period structure to an intimate relation between alloy Fermi surface and Brillouin zone boundaries. Kádár et $a l .{ }^{3)}$ proposed on the basis of neutron diffraction measurements a structure model for the phase $\mathrm{Pd}_{2} \mathrm{Mn}$, whose existence was found in an earlier study of Raub and Mahler ${ }^{4)}$ as $\beta_{2}$ phase. Kádár and Krén ${ }^{5)}$ also proposed a structure model for the phase $\mathrm{Pd}_{5} \mathrm{Mn}_{3}$. Miida et al. ${ }^{6)}$ made an extensive electron diffraction and microscopic study over the composition range from $\mathrm{Pd}-24 \% \mathrm{Mn}$ to $40 \% \mathrm{Mn}$ and proposed a phase diagram, in which relation among relevant phases is shown.

However, the studies of Watanabe ${ }^{1)}$ and Sato \& Toth $^{2)}$ were performed using thin film samples and there might be uncertainty in the composition. In addition, electron diffraction could not afford, due to strong dynamical effects, quantitative information on the atomic parameters. In Kádár et al.'s neutron diffraction study, only a small number of reflections lying in lower diffraction angle region were used and, therefore, not much accuracy could be attached to the detailed structure data.

Manganese shows, unlike other $3 \mathrm{~d}$ elements, a characteristic behavior as an alloying element and the structure of ordered phases forming in the Mn containing alloys is often of the type not seen in the typical Hume-Rothery alloys. We have performed X-ray diffraction study on the Pd-28 46\%

*Corresponding author, E-mail: ohshima@bk.tsukuba.ac.jp
Mn alloys to furnish precise structure data of the ordered phases and to establish their relation in the phase diagram. Discussion is given on the stability of ordered structures by calculating total energies using density functional method.

\section{Experimental Procedures}

A series of alloys with the compositions of Pd-28.1, 30.8, 33.0, 34.5, 36.0, 37.5, 45.8\% Mn were prepared using the arcmelting technique in a high-purity alumina crucible. The samples were cut in the form of a plate $12 \mathrm{~mm}$ in diameter from the original ingots. After polished, all the samples were capsulated in an evacuated silica tube, annealed at $1273 \mathrm{~K}$ for two days and quenched into iced water. The composition of the samples was determined by an electron probe microanalyser at the Chemical Analysis Center, University of Tsukuba. Data were taken from ten different spots of the sample and the average value was adopted as the alloy composition.

The samples were powdered by filing and heated again in evacuated silica tubes. Further heat treatments were done to attain ordered states in the high temperature region at $1073 \mathrm{~K}$ for 5 days for $\mathrm{Pd}-30.8$ and $33.0 \% \mathrm{Mn}$ and at $1273 \mathrm{~K}$ for 3 days for Pd-28.1, 36.0, 37.5, and 45.8\% Mn, followed by quenching into iced water. To attain ordered states at lower temperatures, annealing was made at $673 \mathrm{~K}$ for 3 months for Pd-33.0\% Mn, at $923 \mathrm{~K}$ for 3 weeks for Pd-30.8 and $34.5 \%$ $\mathrm{Mn}$ and at $773 \mathrm{~K}$ for 3 weeks for Pd-28.1, 36.0, 37.5, and $45.8 \% \mathrm{Mn}$, followed by slow cooling to room temperature.

$\mathrm{X}$-ray diffraction measurements were performed at room temperature employing a two-circle diffractometer (PANalytical PW 3050 X'Pert Pro) installed at a line focus $\mathrm{X}$-ray generator. A reflection-free $\mathrm{Si}$ plate was used as a sample stage. $\mathrm{CuKa}$ radiation obtained by reflection from a singly bent HOPG crystal was used. Diffraction pattern was recorded using a solid state detector (PANalytical $X^{\prime}$ Celerator) with a scan speed of $0.5 \mathrm{deg}$. (in $2 \theta$ ) $/ \mathrm{min}$. up to 150 degrees. Repeated collection of the diffraction data was 
Table 1 Lattice parameters of the alloys investigated in the present study.

\begin{tabular}{|c|c|c|c|c|c|c|}
\hline at $\% \mathrm{Mn}$ & Temperature (K) & Structure & Space Group & $a(\mathrm{~nm})$ & $b(\mathrm{~nm})$ & $c(\mathrm{~nm})$ \\
\hline \multirow[t]{2}{*}{28.1} & 1273 & fcc & Fm-3m (225) & 0.3940 & & \\
\hline & 773 & $\mathrm{DO}_{23}$ & $\mathrm{I} 4 / \mathrm{mmm}(139)$ & 0.3904 & & 1.5624 \\
\hline \multirow[t]{3}{*}{30.8} & 1073 & $\mathrm{fcc}^{*}$ & & 0.3918 & & \\
\hline & & $\mathrm{L}_{0} *$ & & 0.4015 & & 0.3723 \\
\hline & 923 & $\mathrm{DO}_{23} *$ & & 0.3947 & & 1.5306 \\
\hline \multirow[t]{2}{*}{33.0} & 1073 & $\mathrm{L1}_{0}$ & $\mathrm{P} 4 / \mathrm{mmm}(123)$ & 0.4024 & & 0.3694 \\
\hline & 673 & $\mathrm{Pd}_{2} \mathrm{Mn}$ & Pnma(62) & 0.5473 & 0.4055 & 0.8151 \\
\hline \multirow[t]{2}{*}{34.5} & 923 & $\mathrm{Pd}_{2} \mathrm{Mn}^{*}$ & & 0.5449 & 0.4066 & 0.8152 \\
\hline & & $\mathrm{L}_{0} *$ & & 0.4038 & & 0.3666 \\
\hline \multirow[t]{2}{*}{36.0} & 1273 & $\mathrm{~L} 1_{0}$ & $\mathrm{P} 4 / \mathrm{mmm}(123)$ & 0.4051 & & 0.3658 \\
\hline & & $\mathrm{Pd}_{5} \mathrm{Mn}_{3}{ }^{*}$ & & 0.8109 & 0.4061 & 0.7245 \\
\hline \multirow[t]{2}{*}{37.5} & 1273 & $\mathrm{~L}_{0}$ & $\mathrm{P} 4 / \mathrm{mmm}(123)$ & 0.4052 & & 0.3652 \\
\hline & 773 & $\mathrm{Pd}_{5} \mathrm{Mn}_{3}$ & $\mathrm{Bmmm}(65)$ & 0.8107 & 0.4053 & 0.7263 \\
\hline \multirow[t]{2}{*}{45.8} & 1273 & $\mathrm{~L} 1_{0}$ & $\mathrm{P} 4 / \mathrm{mmm}(123)$ & 0.4068 & & 0.3625 \\
\hline & 773 & $\mathrm{~L} 1_{0}$ & $\mathrm{P} 4 / \mathrm{mmm}(123)$ & 0.4053 & & 0.3610 \\
\hline
\end{tabular}

*two-phase mixture.

made after repacking powdered samples until the effect of preferred orientation of grains became minimum. Rietveld refinement was done for the intensity profile in the whole $2 \theta$ range using the program RIETAN written by Izumi and Ikeda. ${ }^{7)}$

\section{Results and Analysis}

\subsection{Structure of the alloys at high temperatures}

X-ray powder diffraction patterns of Pd-28.1 and 30.8\% Mn alloys, both of which annealed at $1273 \mathrm{~K}$ and quenched, show that the structures are fcc, in agreement with the earlier phase assignment. ${ }^{8)}$ Diffraction patterns of Pd-36.0, 37.5 and $45.8 \% \mathrm{Mn}$ alloys annealed at $1273 \mathrm{~K}$ are those expected from the $\mathrm{L} 1_{0}$-type structure (or tetragonally distorted B2-type structure), also in agreement with the earlier phase assignment. ${ }^{8)}$ Diffraction pattern taken for the alloy of $30.8 \% \mathrm{Mn}$ annealed at $923 \mathrm{~K}$ shows a two-phase mixture of fcc and $\mathrm{L} 1_{0}$, while the pattern of the $33.0 \% \mathrm{Mn}$ alloy shows the existence of only the $\mathrm{L} 1_{0}$-type structure. Since the ideal composition for this structure is $\mathrm{Pd}: \mathrm{Mn}=50: 50$, the excess Pd atoms in the $33.0 \% \mathrm{Mn}$ alloy must occupy the sites of $\mathrm{Mn}$ atoms. Smaller deviation from unity in the c/a axial ratio compared with the axial ratio of the alloys richer in Mn supports this.

Lattice parameter data of the alloys investigated in the present study are listed in Table 1.

\subsection{Structure of $\mathbf{P d}_{3} \mathrm{Mn}$}

Figure 1 shows a diffraction pattern of Pd-28.1\% Mn alloy annealed at $773 \mathrm{~K}$. Refined lattice parameters show that the $\mathrm{M}$ value characterizing the long period is 2.0 in spite of a small deviation in composition from the ideal $\mathrm{Pd}_{3} \mathrm{Mn}$. This supports the fixed M value as revealed by Sato and Toth. ${ }^{2)}$

Sato and Toth $^{2)}$ and Miida et al. ${ }^{6)}$ reported that the $\mathrm{D}_{23}$ type phase exists stably on an increase in the Mn content

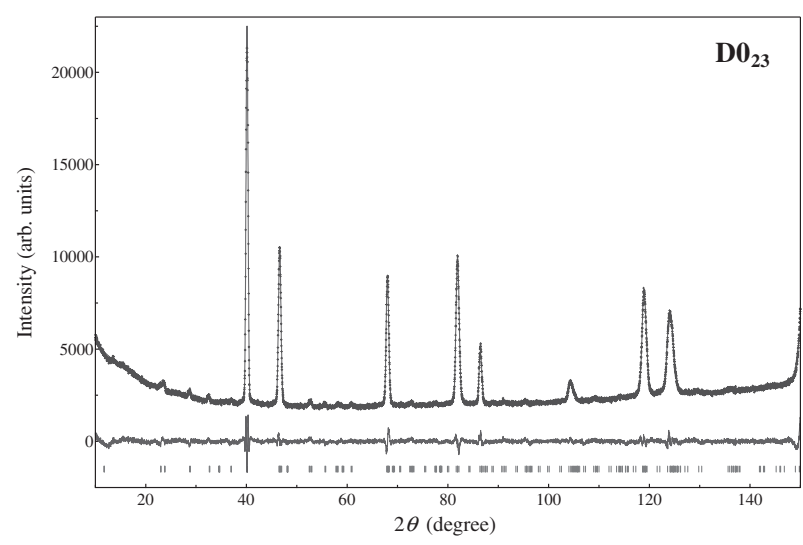

Fig. 1 X-ray diffraction pattern of $\mathrm{Pd}_{0.719} \mathrm{Mn}_{0.281}$ alloy annealed at $773 \mathrm{~K}$. Results of Rietveld refinement are shown below the intensity profile.

and changes continuously into the $\mathrm{L} 1_{0}$-type phase. However, $\mathrm{X}$-ray diffraction pattern obtained in the present study has shown that there is a distinction between the $\mathrm{D}_{23}$-type and $\mathrm{L}_{0}$-type structures in the intensities of superlattice reflections. The $\mathrm{D}_{23}$-type phase exists in a limited range around the composition $25 \% \mathrm{Mn}$.

\subsection{Structure of $\mathbf{P d}_{2} \mathrm{Mn}$}

X-ray diffraction pattern of Pd-33.0\% Mn alloy, which was annealed at $673 \mathrm{~K}$ for 3 months, is shown in Fig. 2. Number of diffraction peaks has increased, indicating that the lattice symmetry is lower. Attempts were made to index sharp diffraction peaks assuming an orthorhombic lattice and good agreement was obtained with the lattice parameters $a=$ $0.5473 \mathrm{~nm}, b=0.4055 \mathrm{~nm}$, and $c=0.8151 \mathrm{~nm}$. They are in the following relation with the fundamental fcc lattice; $a=\sqrt{2} a_{0}, b=a_{0}$, and $c=(3 / \sqrt{2}) a_{0}, a_{0}$ being the lattice 


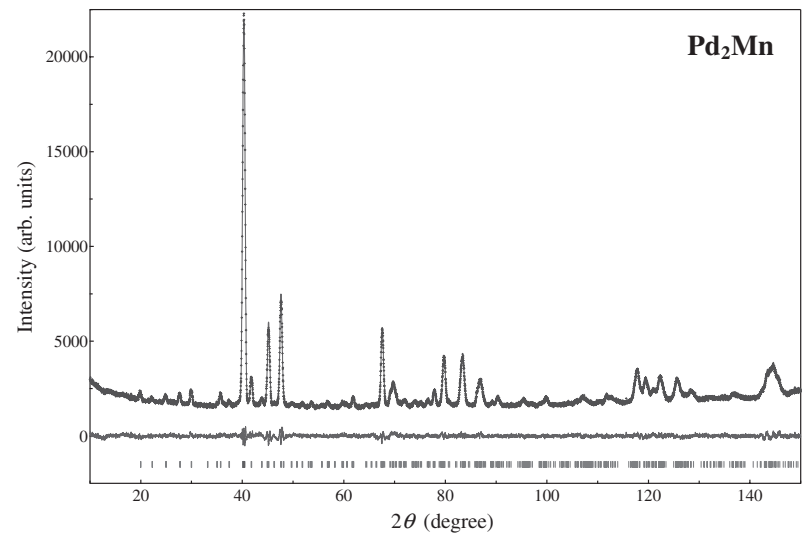

Fig. 2 X-ray diffraction pattern of $\mathrm{Pd}_{0.67} \mathrm{Mn}_{0.33}$ alloy annealed at $673 \mathrm{~K}$. Results of Rietveld refinement are shown below the intensity profile.

Table 2 Refined atomic parameters of $\mathrm{Pd}_{2} \mathrm{Mn}$ (space group Pnma).

\begin{tabular}{cccccc}
\hline Atom & Site & $\mathrm{x}$ & $\mathrm{Y}$ & $\mathrm{Z}$ & $\mathrm{B}\left(\mathrm{nm}^{2}\right)$ \\
\hline $\mathrm{Mn}$ & $4 \mathrm{c}$ & 0.093 & $1 / 4$ & 0.072 & 0.002038 \\
\hline $\mathrm{Pd}(\mathrm{I})$ & $4 \mathrm{c}$ & 0.113 & $1 / 4$ & 0.407 & 0.002312 \\
\hline $\mathrm{Pd}(\mathrm{II})$ & $4 \mathrm{c}$ & 0.162 & $1 / 4$ & 0.746 & 0.002117 \\
\hline
\end{tabular}

parameter of the fundamental lattice. Eight Pd and four $\mathrm{Mn}$ atoms are contained in the unit cell. Systemic extinction is observed such that $0 k l$ reflections with $k+l$ odd are absent and $h k 0$ reflections with $h$ odd are absent. This uniquely leads to the space group Pnma, in accord with the assignment by Kádár et $a l .{ }^{3)}$

Rietveld refinement was done for the intensity profile in the $2 \theta$ range between 10 and 150 degrees. The results are shown at the bottom in Fig. 2. Refined atomic parameters along with thermal parameters are listed in Table 2. The reliability factor $R$ is $3.37 \%$ and the goodness-of-fit indicator $S$ is 1.55 . The atomic arrangements of $\mathrm{Pd}_{2} \mathrm{Mn}$ thus determined are shown projected onto the (010) plane in Fig. 3. The atoms are located at slightly shifted positions from those of the fundamental lattice, the magnitudes of the shifts being $\Delta x=0.0066 \mathrm{~nm}$ and $\Delta z=0.0079 \mathrm{~nm}$ for $\mathrm{Pd}(\mathrm{I})$ atom, $\Delta x=0.0202 \mathrm{~nm}$ and $\Delta z=0.0033 \mathrm{~nm}$ for $\mathrm{Pd}(\mathrm{II})$ atom and $\Delta x=0.0175 \mathrm{~nm}$ and $\Delta z=0.0092 \mathrm{~nm}$ for $\mathrm{Mn}$ atom. The arrows attached to the atoms show the direction of the shifts. An appreciable change has appeared in the directions and magnitudes of the atomic shifts from those obtained by Kádár et al. ${ }^{3)}$

The shifts result in an appreciable contraction of the interatomic distances, particularly those between Mn atoms. It would be $0.2798 \mathrm{~nm}$ in unshifted structure and has become $0.2554 \mathrm{~nm}$ as a result of the shifts. However, if a rigid sphere model is adopted with the radius of $\mathrm{Mn}$ atom of $0.126 \mathrm{~nm},{ }^{9)}$ the distance of contact between $\mathrm{Mn}$ atoms will be $0.252 \mathrm{~nm}$, approximately the same as that observed. The distance $0.2711 \mathrm{~nm}$ between the larger Pd atoms is not much different from the twice of the atomic radius of $\mathrm{Pd}, 0.138 \mathrm{~nm}$.

\subsection{Structure of $\mathrm{Pd}_{5} \mathrm{Mn}_{3}$}

X-ray diffraction pattern of Pd-37.5\% Mn alloy, which

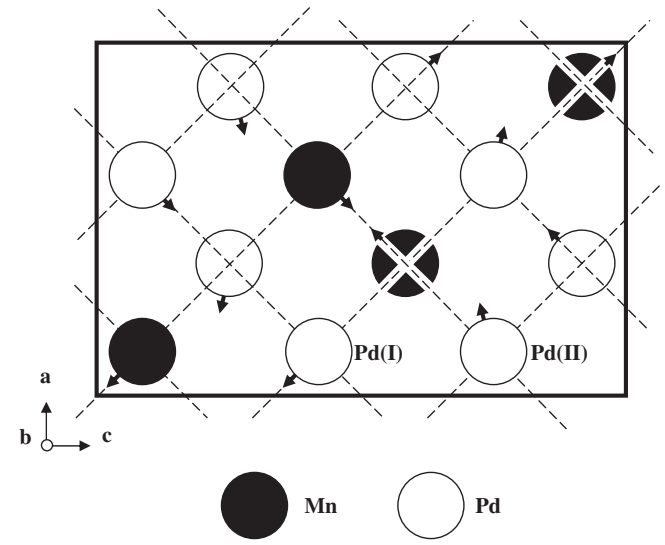

Fig. 3 Structure of $\mathrm{Pd}_{2} \mathrm{Mn}$ determined in the present study. Arrows attached to the atoms represent the direction of the shifts.

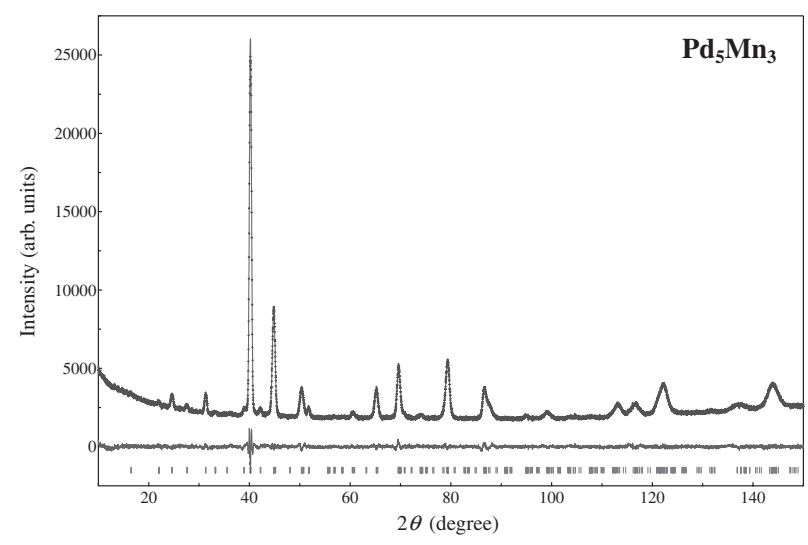

Fig. 4 X-ray diffraction pattern of $\mathrm{Pd}_{0.625} \mathrm{Mn}_{0.375}$ alloy annealed at $773 \mathrm{~K}$. Results of Rietveld refinement are shown below the intensity profile.

was annealed at $773 \mathrm{~K}$ for 3 weeks, is shown in Fig. 4. Sharp peaks can be indexed in terms of the orthorhombic lattice with the lattice parameters of $a=0.8107 \mathrm{~nm}, b=$ $0.4053 \mathrm{~nm}$, and $c=0.7263 \mathrm{~nm}$. They are in rough accord with those reported by Kádár and Krén ${ }^{5)}$ for $\operatorname{Pd}_{5} \mathrm{Mn}_{3}$. The relation between the lattice parameters of $\mathrm{Pd}_{5} \mathrm{Mn}_{3}$ and those of the fundamental fcc lattice is $a=2 a_{0}, b=a_{0}$ and $c \approx 2 a_{0}$. Ten Pd and six Mn atoms are contained in the unit cell. Systematic extinction of the reflections has led to the Bcentered space group Bmmm.

Rietveld refinement was made using observed intensity profile. The results are shown at the bottom in Fig. $4 . R$ is $3.21 \%$ and $S$ is 1.60 . Refined atomic parameters along with thermal parameters are listed in Table 3. The atomic arrangements of $\mathrm{Pd}_{5} \mathrm{Mn}_{3}$ are shown projected onto the (010) plane in Fig. 5. According to Kádár and Krén, ${ }^{5)}$ introduction of atomic shifts and partial mixing of $\mathrm{Pd}$ and $\mathrm{Mn}$ atoms is necessary to get agreement with their observed intensities, but the results of the present structure analysis show that there is no need to introduce mixed occupation of atoms and, furthermore, the shifts of atoms are very small.

\subsection{Reconstruction of the phase diagram}

Taking all the experimental results in the present study into account, partial phase diagram has been reconstructed, as 
Table 3 Refined atomic parameters of $\mathrm{Pd}_{5} \mathrm{Mn}_{3}$ (space group $\mathrm{Bmmm}$ ).

\begin{tabular}{cccccc}
\hline Atom & Site & $\mathrm{x}$ & $\mathrm{Y}$ & $\mathrm{Z}$ & $\mathrm{B}\left(\mathrm{nm}^{2}\right)$ \\
\hline $\mathrm{Mn}(\mathrm{I})$ & $2 \mathrm{a}$ & 0 & 0 & 0 & 0.002030 \\
\hline $\mathrm{Mn}(\mathrm{II})$ & $4 \mathrm{~h}$ & 0.264 & $1 / 2$ & 0 & 0.002041 \\
\hline $\mathrm{Pd}(\mathrm{I})$ & $2 \mathrm{~b}$ & $1 / 2$ & 0 & 0 & 0.002398 \\
\hline $\mathrm{Pd}(\mathrm{II})$ & $4 \mathrm{e}$ & $1 / 4$ & 0 & $1 / 4$ & 0.002444 \\
\hline $\operatorname{Pd}(\mathrm{III})$ & $4 \mathrm{j}$ & 0 & $1 / 2$ & 0.234 & 0.002511 \\
\hline
\end{tabular}

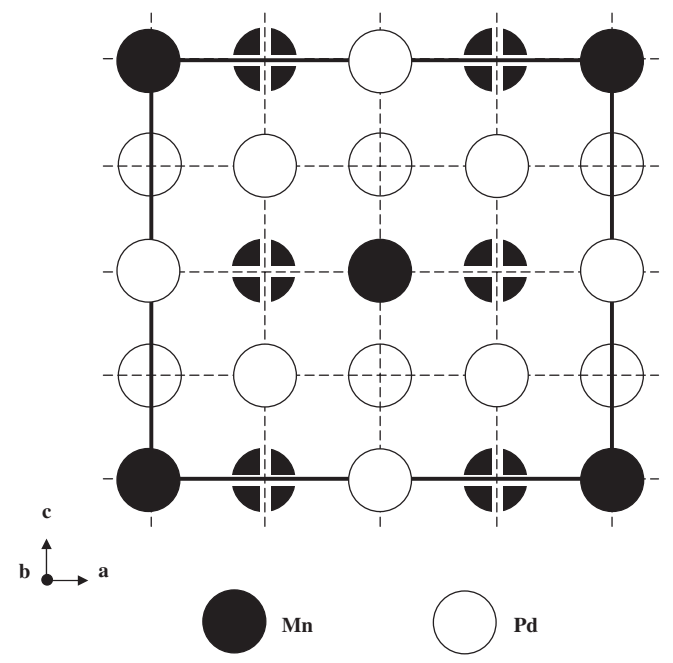

Fig. 5 Structure of $\mathrm{Pd}_{5} \mathrm{Mn}_{3}$. The shifts of atoms are very small, and are not shown in this figure.



Fig. 6 Revised partial phase diagram on the Pd-rich side of Pd-Mn alloy system. The mark $\mathrm{x}$ represents the temperature where the X-ray diffraction pattern was collected.

shown in Fig. 6. General form of the diagram is similar to that proposed by Miida et al., ${ }^{6)}$ but revision has been made in the range of the $\mathrm{DO}_{23}$ phase and the mutual relation among the phases $\mathrm{Pd}_{2} \mathrm{Mn}, \mathrm{Pd}_{5} \mathrm{Mn}_{3}$ and $\mathrm{L1}_{0}$ phase.

\section{Discussion}

\subsection{On the ordered structure of $\operatorname{Pd}_{2} \mathrm{Mn}$ and $\operatorname{Pd}_{5} \mathrm{Mn}_{3}$}

A number of ordered structures are known to form in metallic alloys. The most frequently observed in fcc alloys is of the $\mathrm{L1}_{2}$-type and its representative is $\mathrm{Cu}_{3} \mathrm{Au}$. The

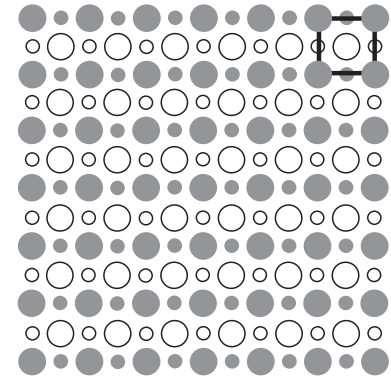

L1 $1_{0}$

(Partial Order)

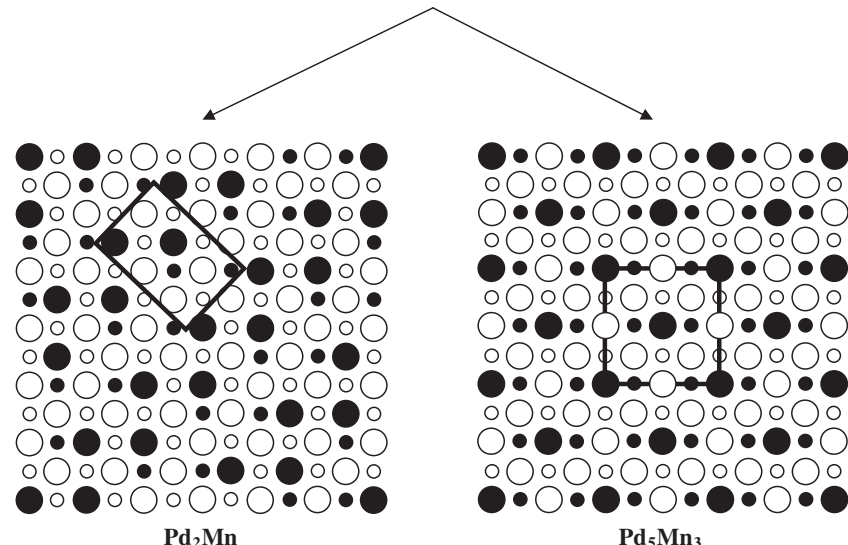

(Perfect Order)

(Perfect Order)

$$
\text { Pd }+ \text { Mn } \bigcirc \bigcirc^{P d} \bigcirc \bullet^{M n}
$$

Fig. 7 Partially ordered $\mathrm{L1}_{0}$-type structure (above), the $\mathrm{Pd}_{2} \mathrm{Mn}$ structure (below left) and the $\mathrm{Pd}_{5} \mathrm{Mn}_{3}$ structure (below right) projected onto the (100) plane. Solid rectangles indicate the unit cells.

same structure is found in noble metal-based alloys and in transition metal-based alloys. Another common ordered structure in fcc alloys is of the $\mathrm{L} 1_{0}$-type, the representative being $\mathrm{CuAu}$ I. These structures have atomic arrangements with as much unlike nearest neighbors as possible and are favorable in view of the nearest-neighbor pairwise interaction energy. The ordered structures forming in the present Pd-Mn alloys show in general the same tendency; $\mathrm{D}_{23}$-type structure, which is based on the $\mathrm{L1}_{2}$-type one, around the composition of $\mathrm{Pd}-25 \% \mathrm{Mn}$ and the $\mathrm{L}_{0}$-type structure in the composition range from $\mathrm{Pd}-33 \% \mathrm{Mn}$ to $50 \% \mathrm{Mn}$. However, the structures $\mathrm{Pd}_{2} \mathrm{Mn}$ and $\mathrm{Pd}_{5} \mathrm{Mn}_{3}$ forming are of the lesscommon type in fcc alloys. Stability of these structures can not be accounted for in the framework of the nearestneighbor interaction model.

Let us consider the mechanism of formation of the structures $\mathrm{Pd}_{2} \mathrm{Mn}$ and $\mathrm{Pd}_{5} \mathrm{Mn}_{3}$. As seen in the phase diagram in Fig. 6, they form on lowering temperature from the $\mathrm{L}_{0^{-}}$ type phase, which contains excess Pd atoms with alternate (001) layers consisting of pure Pd and mixed Mn-Pd planes. The $\mathrm{L}_{0}$-type structure at the compositions of $\mathrm{Pd}-33.3 \% \mathrm{Mn}$ and $\mathrm{Pd}-37.5 \% \mathrm{Mn}$ can be regarded as partly ordered structure. Figure 7 depicts schematically the atomic arrangements of the structure projected onto the (100) plane along with those of $\mathrm{Pd}_{2} \mathrm{Mn}$ and $\mathrm{Pd}_{5} \mathrm{Mn}_{3}$. The sites with mixed occupation are shown by gray circles. It can be seen that the 


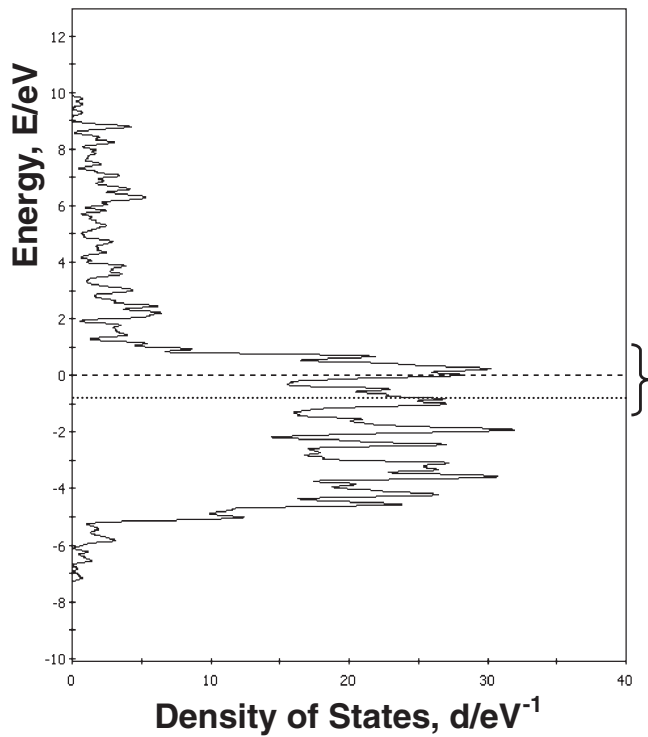

(a)

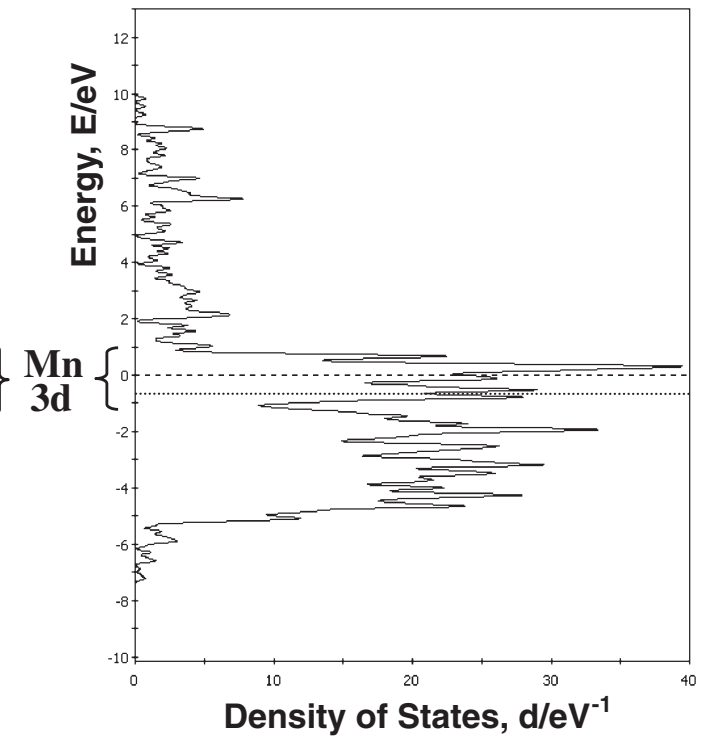

(b)

Fig. 8 The calculated DOS curves for $\mathrm{Pd}_{2} \mathrm{Mn}$ with the shifts of atoms (a) and without them (b). Dot line shows the centre of gravity of the Mn 3d DOS

transition from the $\mathrm{L}_{0}$-type phase into $\mathrm{Pd}_{2} \mathrm{Mn}$ or $\mathrm{Pd}_{5} \mathrm{Mn}_{3}$ involves a redistribution of $\mathrm{Pd}$ and $\mathrm{Mn}$ atoms so that every sites are occupied exclusively either by $\mathrm{Pd}$ or $\mathrm{Mn}$ atom. This transition is a kind of two-step ordering with changing the crystal symmetry. Similar transitions have been reported, for example, in $\mathrm{Fe}-\mathrm{Al}^{10)}$ and $\mathrm{Pt}-\mathrm{Mn}^{11)}$ alloy systems, in which, however, the crystal symmetry does not change.

\subsection{Stability of the ordered structures}

In recent years, there is a remarkable progress in the method of calculating electronic structure of metallic alloys. Hirschl, Hafner and Jeanvoine did ab initio density functional calculations for Pd-V alloys. ${ }^{12}$ ) They could explain stability of the ordered structures of $\mathrm{Pd}_{3} \mathrm{~V}$ ( $\mathrm{DO}_{\mathrm{a}}$-type), $\mathrm{Pd}_{2} \mathrm{~V}\left(\mathrm{MoPt}_{2}-\right.$ type) and $\mathrm{PdV}_{3}$ (A15-type).

We apply the similar method of calculation to the ordered structures forming in the present $\mathrm{Pd}-\mathrm{Mn}$ alloys by using the CASTEP ${ }^{13)}$ program. CASTEP solves the Kohn-Sham equations of local density functional (LDF) theory using a total energy plane-wave pseudopotential method. It replaces core electrons with effective potentials acting only on the valence electrons in the system. Numbers of valence electrons assigned are 10 for $\mathrm{Pd}$ and 7 for $\mathrm{Mn}$ here. The exchange and correlation effects are included in the local density approximations (LDA) and the spin effects are not considered. The ultrasoft pseudopotentials and an energy cutoff of $330 \mathrm{eV}$ are used in calculations. A smearing width of $0.05 \mathrm{eV}$ is used in density of states (DOS).

Band structure and DOS have been calculated for $\mathrm{Pd}_{3} \mathrm{Mn}$, $\mathrm{Pd}_{2} \mathrm{Mn}, \mathrm{Pd}_{5} \mathrm{Mn}_{3}$ and $\mathrm{PdMn}$. For $\mathrm{Pd}_{3} \mathrm{Mn}$, calculation was made not only for the observed $\mathrm{D}_{23}$-type structure but also for the competing ordered structures $\mathrm{DO}_{22}$-type and $\mathrm{L1}_{2}$-type. For $\mathrm{Pd}_{2} \mathrm{Mn}$ and $\mathrm{Pd}_{5} \mathrm{Mn}_{3}$, calculation was made with the shifts of atoms and without them. For PdMn, calculation was made for the $\mathrm{L}_{1}$-type structure and the $\mathrm{B} 2$-type structure. Calculation was also made for Pd and Mn metals.

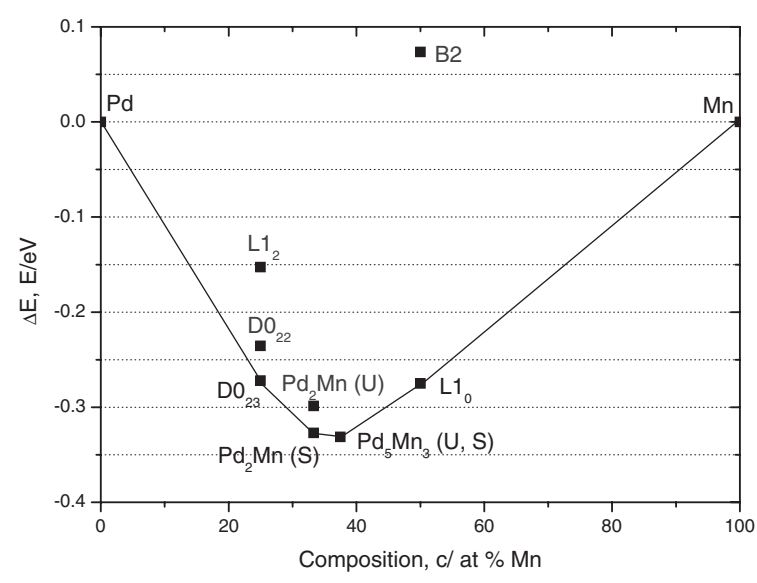

Fig. 9 Formation energy of the ordered structures forming in Pd-riched PdMn alloys. In the figure, $\operatorname{Pd}_{2} \mathrm{Mn}(\mathrm{S})$ and $\mathrm{Pd}_{2} \mathrm{Mn}(\mathrm{U})$ represent the $\mathrm{Pd}_{2} \mathrm{Mn}$ structure with and without the shifts of atoms. There is little difference on formation energy of $\mathrm{Pd}_{5} \mathrm{Mn}_{3}$ between with and without shifts of atoms.

Figure 8 shows the calculated DOS curves for $\mathrm{Pd}_{2} \mathrm{Mn}$ with the shifts of atoms (a) and without them (b). The DOS curve is similar to each other, and the Fermi level is almost same. However, there is a significant difference that the Mn $3 \mathrm{~d}$ band width in (a) is a little larger than in (b). It means larger Mn-Mn interactions due to the shifts of Mn atoms towards each other. As Mn 3d band is partially filled with valence electrons, it crosses the Fermi level with the part above the Fermi level empty. Hence, the larger band width makes the centre of gravity of the Mn 3d DOS (dot line in (a) and (b)) move lower, results in lower energy.

Formation energy is defined as the difference between the total energy of the structure and the composition-weighted mean of the total energies of constituent Pd and Mn metals. Figure 9 shows the formation energy of the ordered structures forming in the Pd-Mn alloy system. Solid lines indicate 
the stable structures at low temperature. There is little difference on formation energy of $\mathrm{Pd}_{5} \mathrm{Mn}_{3}$ between with and without atomic shifts, because atomic shifts are very small. The fact that the B2 structure is energetically unfavorable suggests that hetero coordination is no longer a dominant factor in the chemical bonding, ${ }^{12)}$ which is also found in Pd-V alloy system. The nearest $\mathrm{Mn}-\mathrm{Mn}$ bonds (in $\mathrm{L1}_{0}$ ) afford a lower total energy than Pd-Mn bonds, since Mn 3d band crosses the Fermi level. On the other hand, it is generally accepted that bcc or bcc-based structures allow larger scale of thermal vibration with a decrease in free energy. They are found at high temperatures in many alloy systems, and the same is true for the present Pd-Mn system. Repulsive energy between ion cores has not been included in the above calculation, but it can be concluded that main origin of the stability of the ordered structures comes from the electronic energy.

\section{Summary}

We have performed X-ray powder diffraction experiments on $\mathrm{Pd}$-rich $\mathrm{Pd}-\mathrm{Mn}$ alloys within the composition range of $\mathrm{Pd}-28 \sim 46 \% \mathrm{Mn}$. The existence of the $\mathrm{DO}_{23}$-type ordered structure at the composition near $\mathrm{Pd}-25 \% \mathrm{Mn}$, the $\mathrm{Pd}_{2} \mathrm{Mn}$ structure near $\mathrm{Pd}-33 \% \mathrm{Mn}$, the $\mathrm{Pd}_{5} \mathrm{Mn}_{3}$ structure near Pd$37 \% \mathrm{Mn}$, and the $\mathrm{L}_{1}$-type structure from $\mathrm{Pd}-33 \sim 46 \% \mathrm{Mn}$ in the temperature region between $1000 \mathrm{~K}$ and $1273 \mathrm{~K}$, has been confirmed. The precise determination of atomic parameters has been made for these structures, and the detailed phase relation in the Pd-rich region has been constructed. We have also noticed the remarkable atomic shifts between Mn-Mn pairs in $\mathrm{Pd}_{2} \mathrm{Mn}$ structure, in which the movements towards each other in $\mathrm{Mn}$ atoms pair are firstly explained by atoms' hard sphere model pictorially.

The two-step ordering transitions are found in $\mathrm{Pd}_{2} \mathrm{Mn}$ and $\mathrm{Pd}_{5} \mathrm{Mn}_{3}$ compositions. The atomic arrangements in $\mathrm{Pd}_{2} \mathrm{Mn}$ structure are complicated compared with other fcc-based structures. The origin of phase transition from $\mathrm{L}_{0}$-type structure to the $\mathrm{Pd}_{2} \mathrm{Mn}$ structure is not yet fully understood, and remains as a future task.
The phase stabilities of the ordered structures have been discussed from the electronic structures based on density functional method. Formation energies are calculated for all observed structures, and also for some possible structures which are not observed. The tendency of more and shorter Mn-Mn bonds was found and explained by the reduction of total energy, resulting from the interactions of about halffilled Mn 3d electrons.

More accurate electronic structural studies using an allelectron method with spin effects and more complicated approximations, e.g., the generalized gradient approximation (GGA), are necessary to obtain complete structural characteristics on phase change.

\section{Acknowledgments}

We gratefully acknowledge Prof. Nobuhiko Kobayashi of University of Tsukuba for his computer and software supports in an electronic structure calculation.

\section{REFERENCES}

1) D. Watanabe: Trans. JIM 3 (1962) 234-236.

2) H. Sato and R. S. Toth: Phys. Rev. 139A (1965) 1581-1593.

3) G. Kádár, E. Krén and M. Marton: J. Phys. Chem. Solids 33 (1972) 212-215.

4) E. Raub and W. Mahler: Z. Metallkde. 45 (1954) 430-436.

5) G. Kádár and E. Krén: Solid State Commun. 11 (1972) 933-936.

6) R. Miida, T. Tajima, D. K. Saha, M. Y. Wey, D. Watanabe and K. Ohshima: Mater. Trans. 45 (2004) 2822-2825.

7) F. Izumi and T. Ikeda: Mater. Sci. Forum 321-324 (2000) 198.

8) M. Hansen and K. Anderko: Constitution of Binary Alloys, 2nd ed. (McGraw-Hill, New York, 1958) p. 944.

9) C. Kittel: Introduction to Solid Sate Physics, 6th ed., (John Wiley \& Sons, New York, 1986) p. 76.

10) A. Taylor and R. M. Jones: J. Phys. Chem. Solids 6 (1958) 16-37.

11) M. Takahashi, A. K. Das, R. Nakamura, H. Iwasaki, T. Shishido and K. Ohshima: J. Phys. Soc. Jpn. 75 (2006) 013601-1-4.

12) R. Hirschl, J. Hafner and Y. Jeanvoine: J. Phys. Condensed Matter 13 (2001) 3545-3572.

13) M. C. Payne, M. P. Teter, D. C. Allan, T. A. Arias and J. D. Joannopoulos: Rev. Mod. Phys. 64 (1992) 1045-1097. 